\title{
Influence of Fatigability on the Timing of Reassessment in the Treatment of Posterior Canal Benign Paroxysmal Positional Vertigo
}

\author{
Chang-Hee Kim ${ }^{1}$, Jung Eun Shin ${ }^{1}$, Yong Gook Shin ${ }^{2}$, Mee Hyun Song ${ }^{2}$, and Dae Bo Shim ${ }^{2}$ \\ ${ }^{1}$ Department of Otorhinolaryngology-Head and Neck Surgery, Konkuk University Medical Center, Konkuk University \\ School of Medicine, Seoul; and ${ }^{2}$ Department of Otorhinolaryngology-Head and Neck Surgery, Myongji Hospital, Goyang, Korea
}

\section{후반고리관 양성돌발두위현훈의 치료에서 재평가 시기에 대한 피로 현상의 영향}

김창희 ${ }^{1} \cdot$ 신정은 $^{1} \cdot$ 신용국 $^{2} \cdot$ 송미현 $^{2} \cdot$ 심대보 $^{2}$

건국대학교 의학전문대학원 이비인후-두경부외과학교실, ${ }^{1}$ 명지병원 이비인후과 ${ }^{2}$

Received May 28, 2018

Revised August 22, 2018

Accepted September 3, 2018

Address for correspondence

Dae Bo Shim, MD PhD

Department of Otorhinolaryngology-

Head and Neck Surgery,

Myongji Hospital, 55 Hwasu-ro,

14beon-gil, Deogyang-gu,

Goyang 10475, Korea

Tel $+82-31-810-5451$

Fax $+82-31-969-0500$

E-mail lovend77@gmail.com
Background and Objectives The early assessment of treatment is not done for benign paroxysmal positional vertigo (BPPV) since the well-known phenomenon of fatigability after a repeated positional test can mimic successful treatment. The aim of this study is to evaluate the clinical implication of 'fatigability' after Epley maneuver and to identify the therapeutic efficacy of Epley maneuver in posterior canal BPPV (PC-BPPV).

Subjects and Method This study was prospectively conducted by two dizziness clinics on 51 consecutive patients diagnosed with PC-BPPV. All patients included in the study received Epley maneuver treatment. The therapeutic results were reassessed immediately after a single trial of Epley maneuver. After 30 minutes, results were reassessed repeatedly to confirm the fatigability of diagnostic procedure immediately after treatment. If the treatment was not successful after 30 minutes, Epley maneuver was repeatedly performed until complete resolution. Results Immediately after the first maneuver, 45 of $51(88.2 \%)$ patients had neither vertigo nor nystagmus during the positional test. All patients demonstrated complete resolution after receiving one to three Epley maneuvers on the day of diagnosis. 'Fatigability (false negative result)' was confirmed for only one case (1 of 6 patients, $16.7 \%$ ), in which nystagmus was observed after 30 minutes but not identified immediately after the first Epley maneuver.

Conclusion The therapeutic efficacy of Epley maneuver is very high in PC-BPPV. Considering the possibility of fatigability when reassessment is performed immediately after therapeutic maneuver, clinicians should avoid assessing the outcome immediately after treatment in patients with PC-BPPV.

Korean J Otorhinolaryngol-Head Neck Surg 2018;61(12):658-62
서 론

양성돌발두위현훈(benign paroxysmal positional vertigo, $\mathrm{BPPV})$ 은 가장 흔한 재발성 말초 전정 질환으로, 자세 변화에

This is an Open Access article distributed under the terms of the Creative Commons Attribution Non-Commercial License (https://creativecommons.org/licenses/by-nc/4.0) which permits unrestricted non-commercial use, distribution, and reproduction in any medium, provided the original work is properly cited.
의해 반복적으로 발생하는 현훈과 안진을 특징으로 한다. ${ }^{1)}$ $\mathrm{BPPV}$ 는 주로 이석이 난형낭반으로부터 분리되어 각 반고리 관으로 들어감으로써 발생한다. BPPV의 진단은 체위검사 시 나타나는 전형적인 체위현훈과 각 반고리관의 특징적인 체위 안진을 통해 가능하다. ${ }^{2)}$ 체위안진의 분석은 대개 잠복기, 지 속시간, 피로 현상과 전형적인 안진 형태를 통해 이루어진다. 피로 현상은 반복적인 체위검사에 의해 현훈과 안진의 강도 
나 지속시간이 감소되는 것을 의미한다. 피로 현상은 후반고 리관 $\mathrm{BPPV}$ (posterior canal BPPV, $\mathrm{PC}-\mathrm{BPPV}$ )에서 나타나 는 편이며, 반면에 수평반고리관 $\mathrm{BPPV}$ (horizontal canal $\mathrm{BPPV}, \mathrm{HC}-\mathrm{BPPV})$ 에서는 쉽게 피로 현상이 나타나지 않는 다. 과거에는 $\mathrm{BPPV}$ 의 진단 기준으로 '안진의 피로 현상'이 포 함되어 있었다.,4) 안진의 피로 현상은 불필요하게 환자를 반 복적인 현훈에 노출하여 불편감을 일으키고, 임상에서 반복 적인 체위검사를 시행해야 하므로 즉각적인 치료를 하는데 방해가 되기 때문에, 2008년 미국 이비인후과학회에서 발표 된 BPPV의 진단 기준에서 배제되었다. ${ }^{5)}$ 피로 현상의 기전을 설명하기 위해 이석의 분산이나 이석 입자의 미로 내의 일부 분 내에 갇힘 등과 같은 몇몇 가설들이 있다.,7)

PC-BPPV의 치료에는 Epley 수기와 Semont 수기가 효과 적인 치료법으로 사용되어 왔다. ${ }^{1,3,5)}$ 특히, Epley 수기의 치료 효 과를 평가하는 많은 무작위대조연구들이 있는데, 1회의 Epley 수기 치료 효과가 60 80\%로 보고된다. ${ }^{8-11)}$ 보통 Epley 수기 시행 직후에 치료 여부를 확인하기 위한 조기 재평가는 시도 하지 않는데, 이는 반복적인 체위검사로 인해 나타난 피로 현 상이 PC-BPPV의 치료 시 나타나는 결과와 유사할 수 있기 때문이다. ${ }^{11)}$

이에 저자들은 PC-BPPV에서 Epley 수기 후에 나타나는 피로 현상의 임상적 의미를 평가하고, Epley 수기의 치료 효과 를 확인해 보고자 하였다.

\section{대상 및 방법}

\section{대 상}

본 연구는 2개의 대학 병원에서 공동으로 진행하였고, 2014 년 8월부터 2015년 9월까지 어지럼을 주소로 내원하여 PC$\mathrm{BPPV}$ 로 진단된 연속적인 51명의 환자들을 대상으로 전향적 연구를 진행하였다. PC-BPPV의 진단은 2008년 미국 이비 인후과학회에서 제시한 $\mathrm{BPPV}$ 의 진료지침에 따라, 문진에서 $\mathrm{BPPV}$ 의 전형적인 체위현훈을 호소하며, Dix-Hallpike 검사 에서 짧은 잠복기를 가지면서 60초 이내의 지속시간을 보이며 전형적인 회전성 상향 안진을 보일 때 확진하였다. 병변의 방 향은 Dix-Hallpike 검사를 시행하였을 때 회전성 안진에서 안 구의 상극(upper pole)이 향하는 아래쪽 귀의 방향을 병변의 방향으로 정하였다. ${ }^{5)}$ 비전형적인 안진 양상을 보이거나, 이전 에 이석정복술의 치료 병력이 있는 자, 동반된 신경학적 또는 정신과적 질환이 있는 자, 다른 말초성 또는 중추성 현훈을 보 이는 자, 두부 외상의 과거력으로 이차성 원인을 갖는 경우는 제외하였다.

\section{치료방법 및 평가}

내원 당일 PC-BPPV로 진단되면, Epley 수기 1회 시행 직후 에, 체위검사를 재시행하여 치료 여부를 평가하였다. 그리고 추 가 치료 없이 30 분 후, 다시 체위검사를 시행하여 PC-BPPV 에 합당한 체위안진 및 현훈이 나타나지 않으면 '완치’로 판정 하였고, 전형적인 회전성 상향 안진이 보이는 경우 치료되지 않은 것으로 판정하고 다시 Epley 수기를 시행했다. 이때, 치 료 직후 평가에서는 안진이 나타나지 않았으나, 치료 30분 후 의 재평가에는 $\mathrm{PC}-\mathrm{BPPV}$ 의 전형적인 안진이 관찰되는 경우 는 '피로 현상'으로 인한 결과로 판정하였다. 치료 결과를 확 인했을 때 완치가 되지 않았으면, Epley 수기를 재시행한 30 분 후 체위검사에서 완치될 때까지 반복해서 Epley 수기를 시 행했다. 30 분 후 재시행한 체위검사에서도 안진이 나타나지 않은 환자들은 7일 이내에 외래에 재방문하도록 하여, 재발 여부를 확인하였다(Fig. 1). 환자들은 Epley 수기 후에 집에서 눕지 않도록 하는 등의 치료 후 지시사항은 받지 않았다. 치료 후 재평가 시에 PC-BPPV의 전형적인 안진은 관찰되지 않으 나 다른 반고리관형 $\mathrm{BPPV}$ 의 특징적인 안진이 관찰되는 경우 를 '반고리관 전환(canal conversion)'으로 정의하였는데, 머리 회전검사(Roll test)에서 전형적인 향지성 방향의 방향변환성 체위안진(direction changing positional nystagmus, DCPN) 이 확인되는 경우를 Geotropic HC-BPPV로, 전형적인 원지성 방향의 DCPN이 확인되는 경우를 Apogeotropic HC-BPPV 로 진단하였다. 반고리관 전환이 나타난 경우, 각 반고리관형 $\mathrm{BPPV}$ 에 맞춰 이석정복술을 시행하였다. $\mathrm{PC}-\mathrm{BPPV}$ 의 경우 Epley 수기를, Geotropic HC-BPPV의 경우 변형 Lempert 수

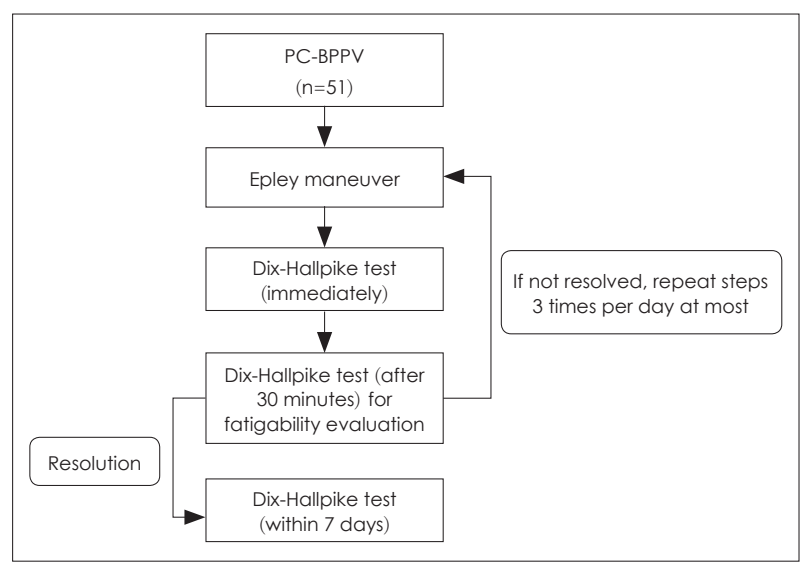

Fig. 1. Study design. Immediately after a single trial of Epley maneuver, reassessment was performed to confirm the therapeutic results. Then, 30 minutes after the first Epley maneuver, reassessment was performed repeatedly to confirm the fatigability of the diagnostic procedure. Epley maneuver was repeatedly performed until complete resolution. Repeated Dix-Hallpike testing to reassess the treatment response was performed at 1-7 days following the therapeutic maneuver. PC-BPPV: posterior canal benign paroxysmal positional vertigo. 
Table 1. Demographic data of patients with PC-BPPV $(n=51)$

\begin{tabular}{lc}
\hline Age (years) & \\
Mean $\pm S D$ & $53.3 \pm 15.4$ \\
Range & $16-85$ \\
Sex $(n, \%)$ & \\
$\quad$ Male & $14(27.5)$ \\
Female & $37(72.5)$ \\
Affected side $(n, \%)$ & \\
$\quad$ Right & $28(54.9)$ \\
Left & $23(45.1)$ \\
Follow up interval (days, mean $\pm S D)$ & $2.5 \pm 1.7$ \\
\hline
\end{tabular}

PC-BPPV: posterior canal benign paroxysmal positional vertigo, SD: standard deviation

기를, Apogeotropic HC-BPPV의 경우 new cupulolith repositioning maneuver를 시행하였다. ${ }^{12)}$ 첫 방문 시 완치판정을 받은 환자들을 1 7일 후 재방문하여 재평가하였을 때, 각 반 고리관형 $\mathrm{BPPV}$ 에 합당한 특징적인 안진이 관찰되는 경우 '재발'로 평가하였다.

본 연구는 건국대학교병원 임상시험위원회(Institutional Review Board)의 윤리 기준에 부합하게 진행되었다(IRB No. KUH1110048).

\section{결 과}

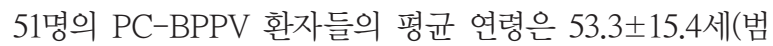
위: 16 85세)였고, 성별은 여자가 37명(72.5\%)으로 남자보다 2.64배 많았다. 병변의 방향은 우측이 28명, 좌측이 23명으로 비슷하였다(Table 1).

전체 51 명의 환자 중 45 명(88.2\%)의 환자들은 1회의 Epley 수기로 치료되었으며(이석정복술 직후와 30분 후 Dix-Hallpike 검사 모두에서 PC-BPPV에 특징적인 체위안진과 현훈 이 사라짐), 모든 환자들은 Epley 수기 3회의 치료로 완치되 었다. 1회로 치료되지 않은 6명 중 4명(7.8\%)은 2회 치료가 필 요하였으며, 2명(4.0\%)만이 3회까지 Epley 수기를 시행하였 다(Fig. 2).

안진의 피로 현상을 확인하였을 때, Epley 수기 직후 평가 에서 특징적인 체위안진 및 증상이 사라진 것으로 확인되었 으나 30 분 후 재평가에서 양성으로 나온 사례가 1 예 있었다 (Table 2).

진단일에 3 명의 환자에서 반고리관 전환이 발생하여, 모두 동측의 Geotropic HC-BPPV 소견을 보였는데, 2명은 내원 당 일 1회 Epley 시행 직후에 나타났고, 1 명은 30 분 후 재시행한 체위검사에서 나타났다. 이 환자들은 모두 변형 Lempert 수기 를 시행하여 완치되었다.

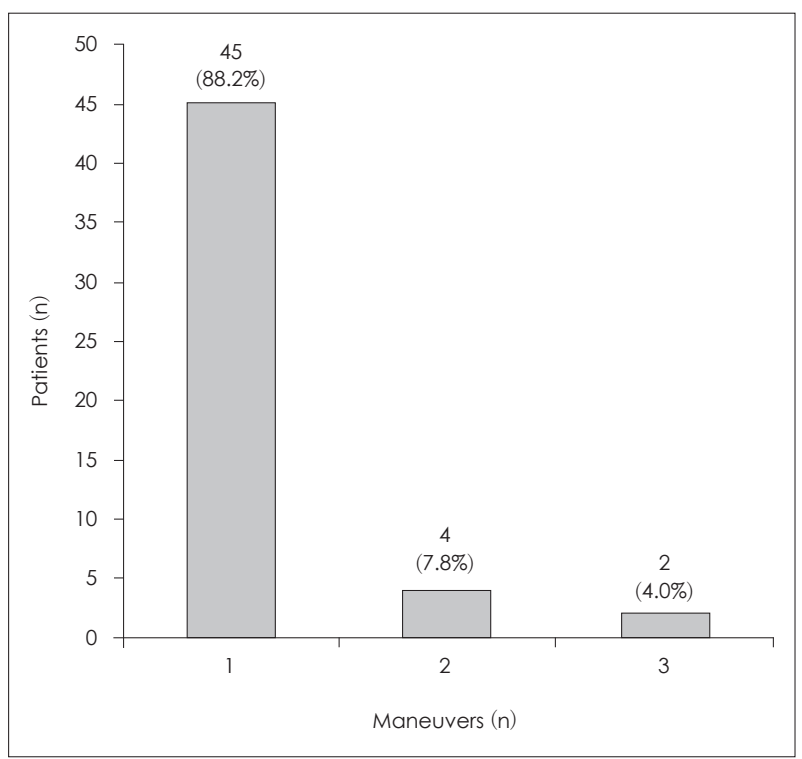

Fig. 2. Response to canalith repositioning maneuver on the initial day. Most patients $(88.2 \%)$ out of total 51 patients demonstrated resolution on the Dix-Hallpike test that was performed immediately after and 30 minutes after the first Epley maneuver. Four patients $(7.8 \%)$ needed one more Epley maneuver. Two patients $(4.0 \%)$ needed to be treated with the Epley maneuver 3 times for complete remission during the initial treatment session.

Table 2. Comparison of re-assessing result between 30 minutes and immediately after Epley maneuver

\begin{tabular}{lccc}
\hline & \multicolumn{2}{c}{30 min after CRP } & \multirow{2}{*}{ Total } \\
\cline { 2 - 3 } & $\mathrm{D}-\mathrm{H}(+)$ & $\mathrm{D}-\mathrm{H}(-)$ & \\
\hline Immediately after CRP $(\mathrm{n}, \%)$ & & & \\
$\mathrm{D}-\mathrm{H}(+)$ & $5(83.3)$ & $0(0)$ & $5(9.8)$ \\
$\mathrm{D}-\mathrm{H}(-)$ & $1(16.7)$ & $45(100)$ & $46(90.2)$ \\
\hline Total & $6(100)$ & $45(100)$ & $51(100)$ \\
\hline
\end{tabular}

Values are presented as number of patients (\%). CRP: canalith repositioning procedure, D-H (-): negative result in Dix-Hallpike test, D-H (+): positive result in Dix-Hallpike test

진단 당일에 완전히 치료된 것을 확인한 후, 1 주일 내에 재 방문하여 재발을 평가하였을 때, 환자들이 재방문할 때까지의 기간은 평균 $2.5 \pm 1.7$ 일이었다. 전체 51 명의 환자 중 5 명 $(9.8 \%)$ 의 환자에서 $\mathrm{BPPV}$ 의 재발을 확인하였는데, 4 명은 $\mathrm{PC}-\mathrm{BPPV}$ 였으나, 1명은 Geotropic HC-BPPV로 확인되었다.

\section{고 찰}

본 연구는 PC-BPPV 환자에서 Epley 수기 직후에 시행하 는 체위검사가 실제 치료 결과를 반영할 수 있는지, 아니면 피 로 현상으로 인해 위음성 결과를 보일 수 있는지 여부를 확인 한 연구이다. 기존에 많은 연구자들은 치료 직후에 피로 현상 으로 인해 치료 효과 판정이 부정확할 수 있다고 하였으나, 이 를 증명한 연구는 거의 없어, 기존의 연구들은 경험적으로 치 
료 후 5 분 또는 10 분 이상의 시간을 두면 피로 현상을 피하여 치료 결과를 확인할 수 있을 것으로 판단하여 이를 적용시켜 왔다.,11)

본 연구에서 Epley 수기 1회 시행 30분 후 평가에서 치료 가 되지 않은 6명 중에서 1명(16.7\%)은 치료 직후 시행한 $\mathrm{Dix}-$ Hallpike 검사에서 PC-BPPV의 특징적인 안진이 관찰되지 않았다. 즉, 1 명이 치료 직후 시행한 체위검사에서 안진의 피 로 현상으로 인해 위음성 결과를 보였고, 이는 PC-BPPV의 Epley 수기 치료 직후에 Dix-Hallpike 검사를 시행하면, 약 $16 \%$ 에서는 실제로 치료가 되지 않았으나 치료가 된 것으로 오진될 소지가 있음을 의미한다.

이러한 안진의 피로 현상을 유발하는 기전은 아직 불확실 하다. 이는 해부학적으로 반고리관이 매우 작고 생체 내에 있 어 연구를 위한 직접적인 실험이나 해부가 불가능하여 정확 한 연구가 어렵기 때문이다. 그러므로, 반고리관 내 팽대부와 이석의 유체 역학에 대한 이해를 도울 수 있는 시뮬레이션이 필요하다. 다행히 이전 연구들에서 안진의 피로 현상을 설명 하는 몇 가지 가설들이 있었다.

한 가지 가설은 반복적인 체위검사로 인해 덩어리 이석 입 자들이 작은 입자들로 분산되어 내림프의 흐름과 팽대부마 루의 휘어짐을 이전보다 약하게 유발한다는 것이다. ${ }^{6,713)}$ Hall 등근 작아진 몇몇 입자들이 미로 내의 일부분에 갇히게 될 수도 있고, 그 결과 더 적은 수의 입자들이 내림프액의 약한 흐름을 만들게 된다고 설명했다. 반면, 다른 연구자들은 이석 입자의 이동 경로가 중요하다고 주장했는데, 그들은 개별 입 자가 반고리관의 중앙부가 아닌 가장자리 쪽에 있거나 반고리 관의 벽에 붙어 있다고 가정해야 중력의 영향을 덜 받게 되는 이석의 궤도가 형성되어 내림프액의 흐름을 적게 유발할 수 있을 것이라고 주장했다. ${ }^{14,15)}$ 또한, Boselli 등든 은 이석 입자 가 팽대부마루로부터 멀어져 가는 이동 방향이 중요하다고 기술했고, 반복적인 체위검사에 의해 오히려 안진의 강도가 커지는 사례들도 보고했다. 이러한 경우는, 이석 입자들이 반 복적인 체위검사에 의해, 제일 처음 내원하였을 때 있던 원래 의 위치로 되돌아간 것이거나, 이석 입자의 궤도가 팽대부마 루의 휘어짐을 증가하게 하는 코스로 변했거나, 아니면 팽대 부마루결석(cupulolithiasis)일 수 있다는 것이다. 더 나아가, 후반고리관은 해부학적으로 팽대부 근처에 직립의 형태 부 분이 있어, 후반고리관 내 이석의 경우에, 머리 움직임에 의 해 이석 입자가 팽대부로부터 멀어지는 방향으로 이동할 경 향이 높을 것이라고 기술했다. ${ }^{16)}$ 다른 연구에서는 습관화 훈련 (habituation training)의 효율성을 설명하기 위해서는 안진 의 피로 현상의 기전에 대해 생각해 보는 것이 필수적이고, 안 진의 피로 현상이 중추성 보상과 관련되어 있을 수 있다고 기
술하였다. ${ }^{17)}$

이렇듯 다양한 여러 가설들이 안진의 피로 현상을 유발하 는 기전에 대한 설명을 시도하고 있지만, 아직 확실한 것은 없 는 상태이다.

우리 연구는 이전에 보고된 다른 연구보다 Epley 수기의 높 은 치료율을 보여준다. Epley 수기의 치료 효율성을 평가하 는 이전의 무작위 대조 연구들은 1 회의 Epley 수기 후의 치 료 성공률을 60 80\%에 이른다고 보고하였다. ${ }^{8-11)}$ 하지만 이 번 연구는 1 회의 치료 성공률이 $88.2 \%$ 로 나타났다. 이는 이 전 연구들은 Epley 수기 시행 후 치료 여부 확인 시점이 치료 직후, 1 일 뒤, 1 주 뒤 등으로 연구마다 다양했다는 점에서 차 이가 발생했을 수 있다. 또, 각 연구들에 참여한 치료자의 숙 련도 차이가 영향을 줄 수 있고, 통계 연구의 특성상, 표본 수 의 차이로 인해 실제 치료율과는 약간씩 다른 결과값의 차이 가 발생할 수도 있다.

본 연구는 몇 가지 제한점을 가지고 있다. 첫째, 본 연구가 전향적인 연구이나, 환자 표본 수가 51명으로 제한적인 환자 수를 대상으로 하여 치료 직후 '피로 현상'을 확인하기 어려 웠다. 추후 PC-BPPV에서 Epley 수기의 치료 실패와 안진의 피로 현상에 대한 연구를 계획한다면, Epley 수기가 1회 치 료만으로도 $80 \%$ 이상의 높은 치료 성공률을 보이기 때문에 모집단에 비해 치료 실패와 안진의 피로 현상에 적용 가능한 환자의 비율이 적으므로, 더 많은 모집단 수로 진행할 필요 가 있겠다. 둘째, 치료 후 안진의 피로 현상을 확인하기 위해 연구 방법론적으로 치료 직후에 재시행한 체위검사가 치료 에 악영향을 주었을 가능성도 있다. 하지만, 본 연구에서 1 회 의 Epley 수기만으로도 $88.2 \%$ 의 높은 치료율을 보인 것은 기존의 연구 결과들과 비교해 보았을 때도 높은 치료 성공률 로서 치료 직후 시행한 체위검사가 큰 영향을 주지 않았을 것 으로 사료된다. 셋째, 치료 직후 1 명의 피로 현상으로 인한 위 음성 결과를 확인하였으나, 방법론적으로 치료 후 안진의 피 로 현상이 사라지는 시점에 대해서는 확인할 수가 없었다. 즉, 본 연구에서는 치료 30 분 후의 평가를 피로 현상이 없는 시점으로 생각하고, 치료 직후에 발생하는 위음성 현상을 찾 고자 하였으므로, 치료 후 어느 정도 시간이 지난 시점에서 실 제로 피로 현상이 사라지는지에 대한 확인은 할 수가 없었다. 넷째, 본 연구는 체위안진의 확인 및 변화에 초점을 두어, 주 관적인 체위현훈의 변화를 통한 피로 현상의 확인은 이루어 지지 않았다. 즉, 내원 첫날에 치료 성공을 확인한 후 다음 외래 내원일까지의 평균 기간이 2.5 일로, 2.5 일보다 짧은 기간 내에 재시행한 체위검사에서 다시 양성 소견이 보인 환자의 경우에, 만약 실제로는 피로 현상이 30분 이상 지속된다면 치료 1 2일 후 재방문하여 재발로 확인된 환자들의 경우, 재 
발인지 피로 현상인지에 대한 판단이 어렵다. 하지만, 본 연 구는 기존에 PC-BPPV에서의 피로 현상에 대한 임상 연구가 없었던 점을 고려할 때, 첫 번째 연구로서 의미가 있다.

Epley 수기는 PC-BPPV에서 1번의 치료로 $80 \%$ 이상의 높 은 치료율을 보이는 효율적인 치료법이다. 하지만 치료 후 결 과를 평가할 때, 치료 직후와 같이 너무 이른 시점에 재평가 를 시행하면 안진의 피로 현상이 발생할 수 있다. 본 연구를 통해 피로 현상을 피할 수 있는 정확한 재평가 시점을 정할 수 는 없지만, 치료 30 분 이후에 재평가를 시행하는 것이 피로 현 상을 피하는 데 도움이 될 것으로 사료된다.

\section{Acknowledgments}

This paper was supported by Konkuk University in 2018 .

\section{REFERENCES}

1) Kim JS, Zee DS. Clinical practice. Benign paroxysmal positional vertigo. N Engl J Med 2014;370(12):1138-47.

2) von Brevern $M$, Bertholon $P$, Brandt $T$, Fife $T$, Imai $T$, Nuti $D$, et al. Benign paroxysmal positional vertigo: diagnostic criteria. J Vestib Res 2015;25(3-4):105-17.

3) Furman JM, Cass SP. Benign paroxysmal positional vertigo. N Engl J Med 1999;341(21):1590-6.

4) Büttner U, Helmchen C, Brandt T. Diagnostic criteria for central versus peripheral positioning nystagmus and vertigo: a review. Acta Otolaryngol 1999;119(1):1-5.

5) Bhattacharyya N, Baugh RF, Orvidas L, Barrs D, Bronston LJ, Cass $\mathrm{S}$, et al. Clinical practice guideline: benign paroxysmal positional vertigo. Otolaryngol Head Neck Surg 2008;139 (5 Suppl 4):S47-81.

6) Brandt T, Steddin S. Current view of the mechanism of benign paroxysmal positioning vertigo: cupulolithiasis or canalolithiasis? J
Vestib Res 1993;3(4):373-82.

7) Hall SF, Ruby RR, McClure JA. The mechanics of benign paroxysmal vertigo. J Otolaryngol 1979;8(2):151-8.

8) Gaur S, Awasthi SK, Bhadouriya SK, Saxena R, Pathak VK, Bisht M. Efficacy of Epley's maneuver in treating BPPV patients: a prospective observational study. Int J Otolaryngol 2015;2015:487160.

9) Lee JD, Shim DB, Park HJ, Song CI, Kim MB, Kim CH, et al. A multicenter randomized double-blind study: comparison of the Epley, Semont, and sham maneuvers for the treatment of posterior canal benign paroxysmal positional vertigo. Audiol Neurootol 2014;19(5): $336-41$.

10) Waleem SS, Malik SM, Ullah S, Hassan Z. Office management of benign paroxysmal positional vertigo with Epley's maneuver. J Ayub Med Coll Abnbottabad 2008;20(1):77-9.

11) von Brevern M, Seelig T, Radtke A, Tiel-Wilck K, Neuhauser $H$, Lempert T. Short-term efficacy of Epley's manoeuvre: a double-blind randomised trial. J Neurol Neurosurg Psychiatry 2006;77(8):980-2.

12) Kim SH, Jo SW, Chung WK, Byeon HK, Lee WS. A cupulolith repositioning maneuver in the treatment of horizontal canal cupulolithiasis. Auris Nasus Larynx 2012;39(2):163-8.

13) Parnes LS, Agrawal SK, Atlas J. Diagnosis and management of benign paroxysmal positional vertigo (BPPV). CMAJ 2003;169(7): 681-93.

14) Hain TC, Squires TM, Stone HA. Clinical implications of a mathematical model of benign paroxysmal positional vertigo. Ann N Y Acad Sci 2005;1039:384-94.

15) Squires TM, Weidman MS, Hain TC, Stone HA. A mathematical model for top-shelf vertigo: the role of sedimenting otoconia in BPPV. J Biomech 2004;37(8):1137-46.

16) Boselli F, Kleiser L, Bockisch CJ, Hegemann SC, Obrist D. Quantitative analysis of benign paroxysmal positional vertigo fatigue under canalithiasis conditions. J Biomech 2014;47(8):1853-60.

17) Sato S, Ohashi T, Koizuka I. Physical therapy for benign paroxysmal positional vertigo patients with movement disability. Auris Nasus Larynx 2003;30 Suppl:S53-6. 